\title{
Immunohistochemical demonstration of c-myc gene product in tumors induced in nude mice by human hepatoblastoma: A study with antiserum to a related synthetic peptide
}

\author{
Toshimitsu Suzuki ${ }^{1,2}$, Chizuko Yanaihara ${ }^{3,4}$, Masayuki Hirota ${ }^{1}$, Makoto Iwafuchi ${ }^{1}$, \\ Takashi Inoue ${ }^{3}$, Tohru Mochizuki ${ }^{3}, \mathrm{KazuaKi} \mathrm{IguChI}^{3}, \mathrm{KaORU} \mathrm{AbE}^{5}$ and \\ NOBORU YANAIHARA ${ }^{2,3}$ \\ ${ }^{1}$ Departments of Pathology and Pediatric Surgery, Niigata University School of Medicine, Niigata 951, \\ ${ }^{2}$ Laboratory of Cellular Metabolism, National Institute for Physiological Sciences, Okazaki $444,{ }^{3}$ Labora- \\ tory of Bioorganic Chemistry, Shizuoka College of Pharmacy, Shizuoka 422, and ${ }^{5}$ Endocrinology Division, \\ National Cancer Center, Research Institute, Tokyo 104, Japan
}

\begin{abstract}
Antiserum to synthetic pentadecapeptide corresponding to the 423-437 sequence of putative human c-myc gene product stained cells in a human hepatoblastoma transplanted in athymic nude mice. The immunostained cells were found in clusters and mainly distributed in areas adjacent to the blood vessels and lakes. The immunoreactive elements were localized in the cytoplasm of the tumor cells.
\end{abstract}

Cellular myc (c-myc) gene is a homolog of avian MC29 viral transforming gene (v-myc). The nucleotide sequence of human c-myc oncogene has been determined by the gene cloning technique $(2,12)$ and the protein coded by the gene was deduced to consist of 439 amino acid residues. On the basis of the structural information of human c-myc gene product, we synthesized a pentadecapeptide corresponding to the C-terminal 423-437 sequence of the predicted protein and produced an antiserum against the synthetic peptide. With use of the antiserum the presence of c-myc-related protein was demonstrated immunohistochemically in a human hepatoblastoma heterotransplanted in athymic nude mice.

A pentadecapeptide corresponding to the 423-437 sequence of human c-myc protein, $\mathrm{H}$ Arg-Arg-Glu-Gln-Leu-Lys-His-Lys-Leu-GluGln-Leu-Arg-Asn-Ser-OH, was prepared by a solid-phase technique (7) with a Beckman

${ }^{4}$ To whom correspondence and requests for reprints should be addressed model 990B peptide synthesizer. After extensive purification by gel filtration and reversephase high performance liquid chromatography, purity of the peptide was assessed by routine analytical criteria. An antiserum (R5452) was produced in a rabbit using the synthetic pentadecapeptide conjugated with Ascaris protein as immunogen. A radioimmunoassay was developed with use of the antiserum and radioiodinated synthetic pentadecapeptide as tracer. For comparison, antisera were also produced in rabbits against synthetic tetradecapeptide corresponding to the 166-179 sequence of c-Ki-ras gene protein (9) (antiserum R4203) and synthetic pentadecapeptide corresponding to the 166-180 sequence of c-Ha-ras gene protein (1) (antiserum R4199). Each of the synthetic peptides related to c-ras gene products was used as immunogen in the form of Ascaris protein conjugate. The anti-synthetic peptide sera R5452, R4203 and R4199 were pretreated with Ascaris carrier protein before their use for immunostaining.

Hepatoblastoma, HBL-2, poorly differentiated type derived from a 19-month-old male 


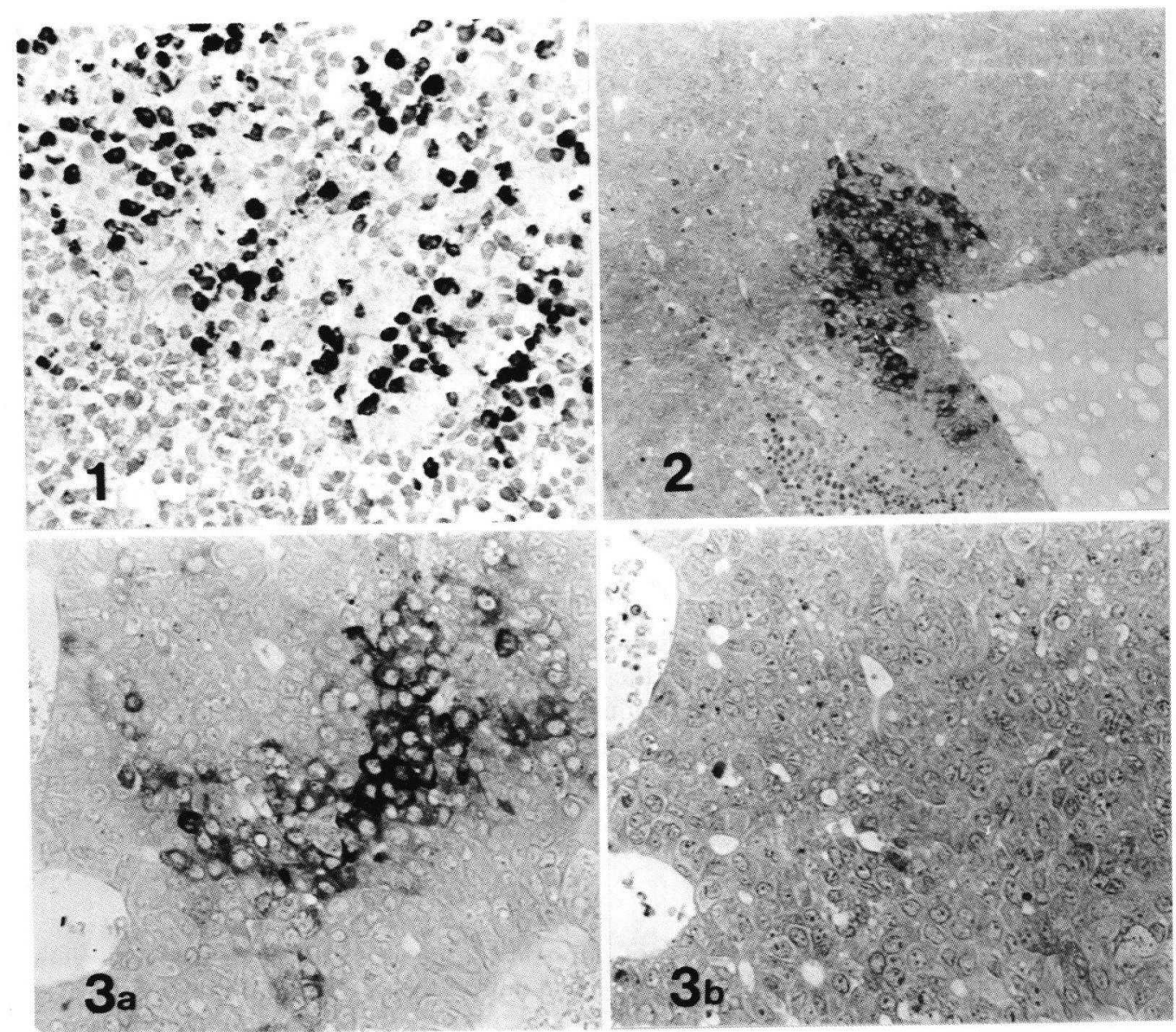

Fig. 1 Immunostaining with antiserum R5452 of a cryostat section of the tumor tissue from a nude mouse transplanted human hepatoblastoma. $\times 200$

Fig. 2 Immunostaining with antiserum R5452 of a paraffin section of the tumor tissue from a nude mouse transplanted human hepatoblastoma. $\times 100$

Fig. 3 Immunostaining with antiserum R5452 (a) and negative control staining (b) of serial paraffin sections of the tumor tissue from a nude mouse transplanted human hepatoblastoma. $\times 200$. For the negative control staining, antiserum R5452 was preincubated with synthetic c-myc related pentadecapeptide.

infant has been serially heterotransplanted in athymic nude mice for 1 year. Radioimmunologically determined serum $\alpha$-fetoprotein level of the tumor-bearing mice ranged from 1,200 to $1,400 \mu \mathrm{g} / \mathrm{mg}$. Extirpated tumor tissues at the 5 th and 6 th passage generation were fixed in $10 \%$ neutral formalin and processed for paraffın wax embedding. Tumor tissues were also treated for cryostat sectioning. Dewaxed paraffin sections ( $4 \mu \mathrm{m}$ thick) and cryostat sections (12 $\mu$ m thick) were stained according to the peroxidase-antiperoxidase (PAP) method using antiserum R5452 (dilution, $1: 2,000)$, antiserum R4203 $(1: 1,000)$ or antiserum R4199 (1:1,000).

We used in this study synthetic pentadecapeptide related to the C-terminal 423-437 part of the predicted protein sequence as haptenic immunogen, in order to obtain C-terminal specific anti-human c-myc protein sera. The extremely C-terminal Cys-Ala in positions 438 and 439 of the protein were not included purposely in the synthesized peptide immunogen because of the functional side chain of Cys residue. A radioimmunoassay with the antiserum recognized solely a 60-65 kDa peak component in Sephadex G150 gel filtration of rat liver extract. Giallongo et al. (3) have demon- 
strated that the antiserum to a synthetic peptide corresponding to the 428-439 human c$m y c$ protein sequence immunoprecipitated a $48 \mathrm{kDa}$ protein from normal and malignant human and mouse B cells.

The present anti-c-myc peptide antiserum R5452 has already been shown to stain numerous cells in a human giant cell carcinoma of the lung transplanted in nude mice, Lu-65, in which amplification of c-myc gene had been proved (6). In this study we observed that antiserum R5452 stains cells in small cell clusters in both cryostat and paraffin sections of the tumor tissues from athymic nude mice transplanted human hepatoblastoma (Figs. 1, 2 and 3a). The staining was completely abolished by pretreatment of the antiserum with the synthetic c-myc related pentadecapeptide (Fig. $3 \mathrm{~b})$. The frequency of immunostained cells was $22.89 \pm 1.03 \%$ in the cryostat sections and $7.47 \pm 2.71 \%$ in the paraffin sections. The clusters of immunostained cells distributed mainly in areas adjacent to the dilated capillaries (Fig. 2) and blood lakes (Fig. 3a). The staining was observed almost exclusively in the cytoplasm of the tumor cells in both sections.

No immunoreactive cells were detected with anti-ras related peptide sera (R4203 and $\mathrm{R} 4199$ ) in either paraffin or cryostat sections of the tumor tissues.

Immunohistochemistry with use of the present antiserum to c-myc peptide provided an additional example of the presence of c-myc gene product or the related protein in tumor cells. The expression of the oncogene seemed to be heterogeneous among cells in the transplanted hepatobalstoma, as in the case of ras gene expression in human mammary and colon carcinomas (4). Conflicting data have been presented with respect to the localization of c-myc gene product in cell nucleus or cytoplasma $(5,6,8,10,11)$. The present immunostaining localized c-myc related protein in the cytoplasma. The intracellular localization of the c-myc gene product still remains to be clarified.

This work was supported by grant-in-aid from the Ministry of Health and Welfare for Comprehensive 10-Year Strategy of Cancer Control, Japan.

Received for publication 7 August 1986

\section{REFERENCES}

1. Capon D. J., Chen E. Y., Levinson A. D., SeeBURG P. H. and GoedDEL D. V. (1983) Complete nucleotide sequences of the T24 human bladder carcinoma oncogene and its normal homologue. Nature 302, 33-37

2. Colby W. W., Chen E. Y., Smith D. H. and LEVINSON A. D. (1983) Identification and nucleotide sequence of a human locus homologous to the v-myc oncogene of avian myelocytomatosis virus MC29. Nature 301, 722-725

3. Giallongo A., appella E., Ricciardi R., Rovera G. and Croce C. M. (1983) Identification of the c-myc oncogene product in normal and malignant B cells. Science 222, 430432

4. Hand P. H., Thor A., Wunderlich D., Muraro R., Caruso A. and Schlom J. (1984) Monoclonal antibodies of predefined specificity detect activated ras gene expression in human mammary and colon carcinomas. Proc. Natl. Acad. Sci. USA 81, 5227-5231

5. Hann S. R., Abrams H. D., Rohrschneider L. R. and Eisenman R. N. (1983) Proteins encoded by v-myc and c-myc oncogenes: identification and localization in acute leukemia virus transformants and bursal lymphoma cell lines. Cell 34, 789-798

6. Iwanaga T., Fujita T., Tsuchinashi T., YamaGUCHI K., ABe K. and Yanaihara N. (1986) Immunocytochemical detection of the c-myc oncogene product in human fetuses. Biomedical Res. 7, 161-166

7. Merrifield R. B. (1963) Solid phase peptide synthesis. J. Amer. Chem. Soc. 85, 2149-2154

8. Rabbitts P. H., Watson J. V., Lamond A., Forster A., Stinson M. A., Evan G., Fischer W., Atherton E., Sheppard R. and Rabbitts T. H. (1985) Metabolism of c-myc gene products: c-myc mRNA and protein expression in the cell cycle. EMBO J. 4, 2009-2015

9. Shimizu K., Birnbaum D., Ruley M. A., Fasano O., Suard Y., Edlund L., Taparowsky E., GoldFarb M. and Wigler M. (1983) Structure of the Ki-ras gene of the human lung carcinoma cell line Calu-1. Nature 304, 497-500

10. Sikora K., Evan G., Stewart J. and Watson J. V. (1985) Detection of the c-myc oncogene product in testicular cancer. Brit. J. Cancer 52, $171-176$

11. Stewart J., Evan G., Watson J. and Sikora K. (1986) Detection of the c-myc oncogene product in colonic polyps and carcinomas. Brit. $J$. Cancer 53, 1-6

12. Watt R., Stanton L. W., Marcu K. B., Gallo R. C., Croce C. M. and Rovera G. (1983) Nucleotide sequence of cloned cDNA of human c-myc oncogene. Nature 303, 725-728 